\title{
Leaching of BPA from Baby Feeding Bottle, Aluminium Can and Thermal Printed Paper: Application of Acridine Orange Oxidation Inhibition method to estimate BPA
}

\author{
Shruti S. Kapse ${ }^{1}$, Kumar Suranjit Prasad ${ }^{2(\mathbb{D})}$, Bablu Prasad ${ }^{1, *(\mathbb{D})}$ \\ 1 Department of Environmental Studies, Faculty of Science, The Maharaja Sayajirao University of Baroda, Vadodara, \\ Gujarat, India, 390002; shruti_kapse@yahoo.com (S.S.K.); \\ 2 Centre of Environmental Studies, Institute of Inter Disciplinary Studies, University of Allahabad, Prayagraj, Uttar Pradesh, \\ India, 211002; ksuranjit@allduniv.ac.in (K.S.P.); \\ * Correspondence: akashganga812@gmail.com (B.P.);
}

Scopus Author ID 56221317400

Received: 10.07.2021; Revised: 20.08.2021; Accepted: 23.08.2021; Published: 11.09.2021

\begin{abstract}
The potential of leaching Bisphenol-A (BPA) from plastic baby feeding bottles, aluminum cans, and thermal printed receipts was investigated under the aquatic condition at high temperatures. BPA is often used to manufacture cross-linked epoxy resin to coat food cans to prevent direct contact with metals and plastic materials. BPA leached from consumer product was analyzed using UV-Visible Spectrophotometer based on the inhibitory effect of BPA on acridine orange oxidation, as a function of change in temperature and time of contact of water with the samples. The proposed method of BPA estimation method was found to be significant and useful for aquatic conditions without any extraction and/or derivatization. The detection limit of BPA under the current experimental setup was $0.1 \mathrm{ng} / \mathrm{ml}$. The results of BPA leached from baby feeding PET bottles, aluminum can with epoxy resin lining, and thermal paper were $87 \pm 10 \mathrm{ng} /$ bottles, $68 \pm 5 \mathrm{ng} /$ bottle, and $110 \pm 15 \mathrm{ng} /$ receipt under the current experimental conditions.
\end{abstract}

Keywords: analysis of bisphenol-A (BPA); UV-visible spectrophotometer; acridine orange oxidation.

(C) 2021 by the authors. This article is an open-access article distributed under the terms and conditions of the Creative Commons Attribution (CC BY) license (https://creativecommons.org/licenses/by/4.0/).

\section{Introduction}

Metals and plastic cans used for food and beverage storage are often internally coated with highly cross-linked thermoset resins materials to avoid undesirable interactions between metals plastics with foods and beverages. Bisphenol-A (BPA) is the most important coatings being used universally for both can bodies and ends for two and three-piece constructions, although more usually for shallow draw cans in the case of two-piece [1,2]. BPA is a highvolume industrial chemical obtained by the condensation of phenol and acetone [3]. The global attention on BPA has increased in recent years due to its potential to interfere with the functioning of endocrine systems [4, 5]. As BPA-based polymers are clear and tough, their application in the manufacturing of food storage containers, including feeding bottles and nonreturnable bottles, has rapidly increased [6]. Furthermore, BPA is also used as a color developer in carbonless copy paper, thermal receipt papers, epoxy-based paints, printing inks, flame retardants, and surface coatings [3, 7,8$]$.

Transport and processing of BPA and consumer products containing BPA are foremost sources of pre-consumer release. However, post-consumer sources include those associated 
with the disposal of waste, including effluent discharge from municipal wastewater treatment plants, leaching from landfills, combustion of domestic waste, and degradation of plastics in the environment $[9,10]$. It is acutely toxic to many organisms and belongs to category 1 of endocrine-disruptive chemicals $[3,11,12]$. In addition, it has been associated with a wide range of adverse effects, including carcinogenesis and increased sensitivity of certain cell types like mammary, epithelial, and thyroid [13, 14]. Dermal and oral exposure is considered to be a main source of human exposure to BPA [15-17]. Recently, it has been estimated that humans take around 1-5 $\mu \mathrm{g}$ BPA $/ \mathrm{kg}$ body weight on a daily basis due to extensive use and disposal of BPAcontaining products [18]. BPA detected in the environmental samples has been well correlated with potential health effects and shown that BPA-exposed factory workers are at greater risk of sexual dysfunction. Epidemiological evidence has shown significant effects on the offspring of parents exposed to BPA during pregnancy [14].

The extensive use of BPA in plastic materials, such as food packaging, tableware, and cookware, has been ubiquitously reported in the environment [19-21]. The survey, assessment, and monitoring of BPA are highly crucial to understand human exposure likelihood. In addition, quantifying trace amounts of BPA leached from food contact materials and other human exposure sources could be crucial to managing these widespread pollutants. Several analytical methods have been developed to monitor BPA in environmental compartments with their limitations, including HPLC, GC-MS, FTIR, and Spectrophotometry [15,19]. However, a UV-Visible Spectrophotometric method based on the inhibitory effect of BPA on acridine orange oxidation with hydroxyl radical was reported to be simple, accurate, and rapid [22]. The major goal of this study is to monitor and analyze the amount of BPA released from the baby feeding plastic bottle, aluminum can, and thermal printed paper in the aquatic phase as a function of time and temperature with the use of a simplified method.

\section{Materials and Methods}

\subsection{Chemicals and materials.}

BPA was purchased from Merck Limited, India. All other chemicals used were of high purity and analytical grade. All experiments were performed in triplicate unless otherwise specified. Baby feeding PET bottle and aluminum can with a carbonated cold drink of $200 \mathrm{ml}$ capacity were purchased from the local market of Vadodara, Gujarat, India (Figure 1). Thermal printed paper of average size $12 \mathrm{~cm}$ x $6 \mathrm{~cm}$ was procured from local markets of Vadodara, Gujarat, India. All the glassware was cleaned with $50 \%$ nitric acid and dried in the oven at $120^{\circ} \mathrm{C}$ before the experiments.

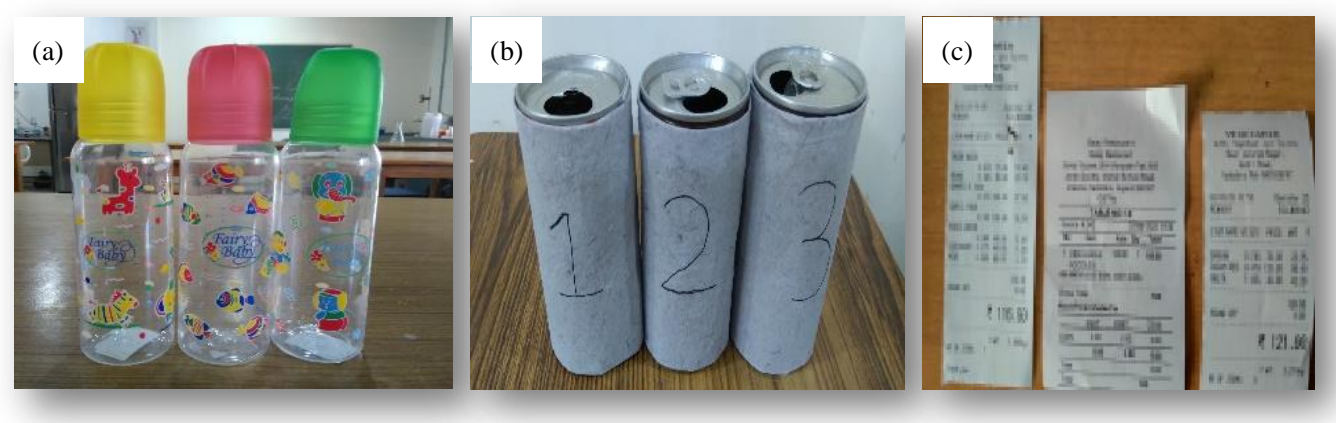

Figure 1. Camera images of consumer products chosen for BPA leachability study under aquatic conditions (a) baby feeding PET bottles (b) aluminum cans and (c) thermal printed paper. 


\subsection{Preparation of samples.}

The thermal printed papers $(12 \mathrm{~cm} \mathrm{X} 6 \mathrm{~cm})$ was emerged in $200 \mathrm{ml}$ deionized water and vigorously mixed at $60^{\circ} \mathrm{C}$. However, in the case of Aluminium cans and baby feeding PET bottles, $200 \mathrm{ml}$ of deionized water was added inside to analyze BPA leached in aquatic conditions at $60^{\circ} \mathrm{C}$. Five $\mathrm{ml}$ samples were aliquoted at specific time intervals up to 96 hours and filtered through $0.45 \mu \mathrm{m}$ filter paper to remove suspended particles before analysis. Nitric acid-treated borosil glass was used as a control.

\subsection{Analysis of BPA.}

The stock solution of $1 \mathrm{mg} / \mathrm{L}$ of BPA was prepared by dissolving BPA in HPLC grade deionized water. In order to homogenize, the stock solution was maintained at $40^{\circ} \mathrm{C}$ for 24 hours with constant stirring on a magnetic stirrer-cum hot plate. The stock solution was kept away from light and stored in a refrigerator. Acridine orange oxidation reaction was set up as per the optimized protocol developed by Zhange et al., 2014 with modification in a $25 \mathrm{~mL}$ volumetric flask under the batch mode containing $0.3 \mathrm{mg}$ Acridine Orange, $1.25 \mathrm{mmole}$ sulfuric acid, 2.5 mmole Ferrous sulfate, and 0.5 mmole $\mathrm{H}_{2} \mathrm{O}_{2}$ in deionized water. In order to find the inhibitory effect of BPA on acridine orange oxidation, varying concentrations of BPA standard solution $(1.0 \mu \mathrm{g} / \mathrm{mL})$ were added to the reaction mixture. A blank experiment was set up with all reaction mixtures except BPA solution to estimate total oxidation without inhibition. To estimate concentrations of BPA in test samples, all the reaction mixtures were added along with $5 \mathrm{~mL}$ of samples in place of standard BPA. The standard, blank, and test solutions were heated in the water bath at $50.0 \pm 0.2^{\circ} \mathrm{C}$ for $10 \mathrm{mins}$ and then allowed to cool down at room temperature before analysis using Agilent Cary $60 \mathrm{UV}$-visible Spectrophotometer. The absorption spectra of standard BPA, blank and test solutions along with the reaction mixture were measured in the range of 200 to $1100 \mathrm{~nm}$ to analyze the inhibitory effect of BPA and test samples. The oxidation rate of the catalytic and non-catalytic reaction was calculated at an absorbance at $265 \mathrm{~nm}$ to estimate the amount of BPA present in the analyzed sample.

\section{Results and Discussion}

The inhibitory effect of BPA on acridine orange oxidation by hydroxyl radical from Fenton reaction in the acid medium was observed to be significant to establish co-relation between trace amount of BPA with oxidation inhibition (Figure 2). Calibration curves were derived from absorbance data at $265 \mathrm{~nm}$ for BPA estimation in the range of $1 \mathrm{ng}$ to $100 \mathrm{ng}$ with a linear correlation coefficient of $>0.94$. Interference due to other inorganic and organic constituents is the major reason for less usage of spectrophotometric techniques for analyzing and monitoring specific chemicals in environmental samples [23]. However, the current method has been reported with insignificant interferences with inorganic constituents. More than 1000 times of $\mathrm{Na}^{+}, \mathrm{K}^{+}$, and $\mathrm{Mn}^{2+}$ than BPA did not show any significant interferences during an analysis of BPA using this method [22]. However, the presence of organic constituents such as phenol, p-nitrophenol, aniline, and salicylic acid up to 5 times than BPA content showed a marginal effect on the accuracy of BPA determination [22].

Baby feeding PET bottles and aluminum can with epoxy resin lining leached $87 \pm 10$ $\mathrm{ng} /$ bottles and $68 \pm 5 \mathrm{ng} / \mathrm{can}$ of BPA, respectively, in the course of 4 days at room temperature followed by heating of 1 hour on day 1 at $60^{\circ} \mathrm{C}$. However, tolerable daily intake (TDI) and 
specific migration limit of BPA have been reported as $4 \mu \mathrm{g} / \mathrm{kg}$ of body weight/day and 0.05 $\mathrm{mg} / \mathrm{kg}$, respectively [24]. On the other hand, the worst-case scenario has been reported to be 1.6 and $0.8 \mu \mathrm{g} / \mathrm{kg}$ of body weight for newly born and infant babies, respectively, by EU risk assessment [9]. Leaching of BPA from polymers and aluminum can has been often linked with manufacturer standards and environmental conditions, including temperature, duration of storage, sunlight, humidity, and contact with other materials [25]. For example, Cooper et al. (2011) has reported in the range of 0.08 to $1.9 \mathrm{mg} / \mathrm{l}$ due to different manufacturers' standards followed during manufacturing of cans and exposure duration and time [26]. In the current investigation, results were consistent with the literature, and the trend of BPA release in baby bottles was increased by more than $54 \%$ from 24 hours to 48 hours. However, the maximum amount of BPA was leached within 96 hours of incubation. Further incubation of baby bottles with water did not show any significant change in the amount of BPA leached. The amount of BPA leached under current experimental conditions is within the safe limit, considering specific migration limits and worst-case scenarios for infants and newborns. Although there was no BPA reported in the detectable range during heating in this study, it could be because the temperature decided was $60^{\circ} \mathrm{C}$ considering real-life conditions as it cannot contain anything boiling hot inside them. There was an increase of $72.7 \%$ in BPA leaching from day 2 to day 4 , which implies that in this particular study, time of contact played a more important role in BPA migration in aluminum cans as compared to rise in temperature if that is the case beverage cans which can be stored in the refrigerator may leach BPA over time even though the temperature is low. Moreover, the method used in this study was only tested on plastic products before, so interferences other than those reported in this paper can play a role in unusual BPA determination. A study conducted by the University of Texas School of Public health in 2010 found BPA in 63 out of 105 samples of fresh and canned foods, including canned infant formula [8]. Intentional heating for sterilization or unintentional heating during storage and transportation of plastic bottles or aluminum cans can release BPA and its derivatives to food and drinks in variable quantities [27].

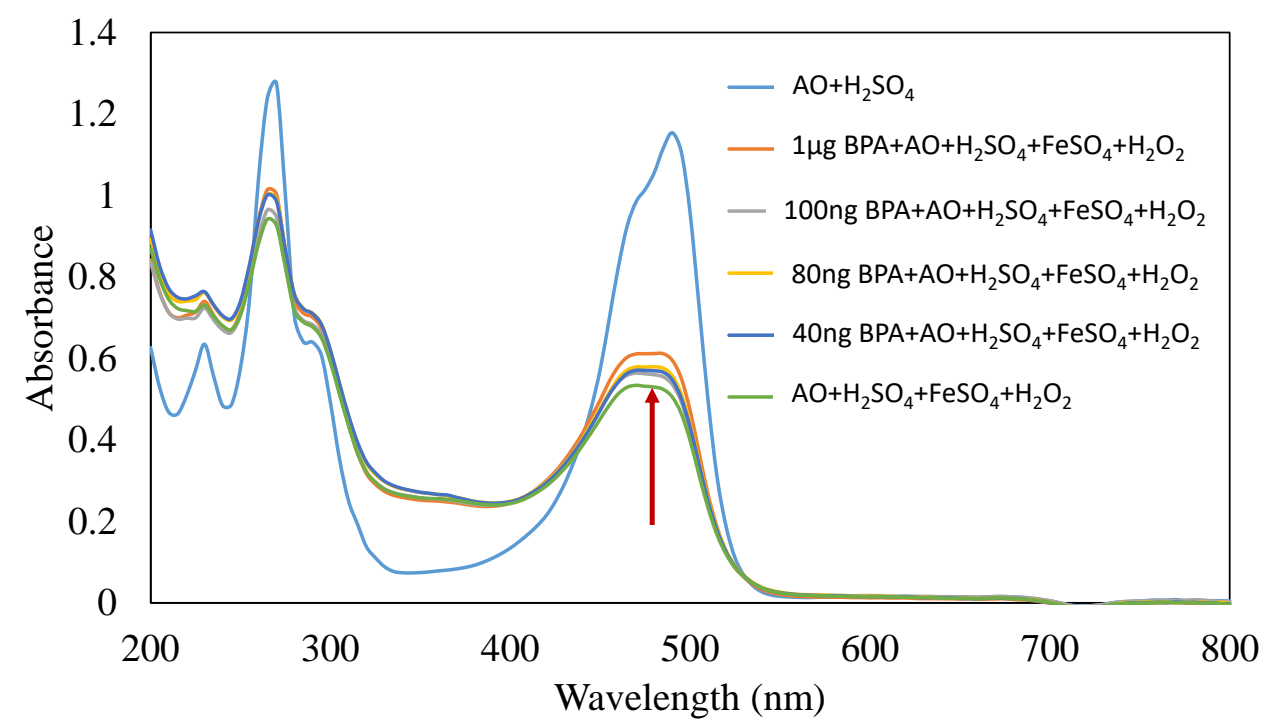

Figure 2. UV-Visible spectrum of acridine orange oxidation by Fenton reagent and their inhibition using BPA.

The results of BPA leached from the thermal paper were $110 \pm 15 \mathrm{ng} /$ receipt considering all the experimental conditions. Although, this method should not be considered very accurate for BPA determination from thermal paper because soaking of paper in water involved 
degradation of paper, and that could have released more materials that would have interacted with the actual concentration of BPA. A comparative study needs to be carried out of BPA determination using the method reported in this study and compare the results with HPLC or other methods. BPA in thermal papers is loosely bounded in monomeric forms that can be readily transferred to any surface that comes in contact, even by touching them with our hands, since leaching of BPA from thermal papers does not require any harsh acidic or heat conditions $[28,29]$. Even though nobody usually soaks thermal papers in water, thermal papers end up in landfill sites and enterwater bodies due to the improper recycling process or bad disposal practices.

\section{Conclusions}

Even trace amount of BPA has an environmental concern since it has been reported to be an effective EDC and has synergistic toxic effects with other chemicals. However, cumulative human exposure should be crucial to understand the overall risk of BPA since it has been reported in all environmental compartments. To understand the environmental fate and transport of BPA, it is crucial to monitor accurately without stringent procedures such as multiple-phase extractions, derivatizations, etc., since it has been reported to be ubiquitous. In addition, monitoring and assessment of leached BPA from consumer products such as baby feeding bottles, aluminum cans, and thermal paper prints are vital to understanding consumer products and associated health risks.

The method used under the current investigation showed a very accurate and significant analysis of BPA up to the nanogram level in environmental samples without any extraction and purification techniques. In this survey, the levels of BPA identified in plastic baby feeding bottles, aluminum cans, and thermal printed receipts are unlikely to be of concern to human health since the results obtained for all the samples were found to be below TDI and SML. As of now, there is no reason for consumers to change their source of canned beverage, feeding bottles, and thermal receipt due to these findings.

\section{Funding}

This research received no external funding.

\section{Acknowledgments}

The authors would like to thank The Maharaja Sayajirao University of Baroda for providing the necessary infrastructure to carry out this research.

\section{Conflicts of Interest}

The authors declare no conflict of interest.

\section{References}

1. Goodson, A.; Summerfield, W.; Cooper, I. Survey of bisphenol A and bisphenol F in canned foods A. Food Addit. Contam. 2002, 19, 796-802, https://doi.org/10.1080/02652030210146837.

2. Stärker, C.; Welle, F. Migration of Bisphenol A from Can Coatings into Beverages at the End of Shelf Life Compared to Regulated Test Conditions. Beverages 2019, 5, https://doi.org/10.3390/beverages5010003.

3. Adeyi, A.A.; Babalola, B.A. Bisphenol-A (BPA) in Foods commonly consumed in Southwest Nigeria and its Human Health Risk. Sci. Rep. 2019, 9, https://doi.org/10.1038/s41598-019-53790-2. 
4. Lauretta, R.; Sansone, A.; Sansone, M.; Romanelli, F.; Appetecchia, M. Endocrine Disrupting Chemicals: Effects on Endocrine Glands. Front. Endocrinol. (Lausanne). 2019, 10, https://doi.org/10.3389/fendo.2019.00178.

5. Frenzilli, G.; Martorell-Ribera, J.; Bernardeschi, M.; Scarcelli, V.; Jönsson, E.; Diano, N.; Moggio, M.; Guidi, P.; Sturve, J.; Asker, N. Bisphenol A and Bisphenol S Induce Endocrine and Chromosomal Alterations in Brown Trout. Front. Endocrinol. (Lausanne). 2021, 12, https://doi.org/10.3389/fendo.2021.645519.

6. Almeida, S.; Raposo, A.; Almeida-González, M.; Carrascosa, C. Bisphenol A: Food Exposure and Impact on Human Health. Compr. Rev. Food Sci. Food Saf. 2018, 17, 1503-1517, https://doi.org/10.1111/15414337.12388.

7. Zhuang, Y.; Zhou, M.; Gu, J.; Li, X. Spectrophotometric and high performance liquid chromatographic methods for sensitive determination of bisphenol A. Spectrochim. Acta. A. Mol. Biomol. Spectrosc. 2014, 122, 153-157, https://doi.org/10.1016/j.saa.2013.11.015.

8. Yousif Hammad, A. Determination Amount of Bisphenol A in Drugs and Water Drinking Container in Khartoum State, Sudan. Int. J. Nutr. Food Sci. 2015, 4, https://doi.org/10.11648/j.ijnfs.20150406.12.

9. Aschberger, K.; Castello, P.; Hoekstra, E.; Karakitsios, S.; Munn, S.; Pakalin, S.; Sarigiannis, D. Bisphenol A and Baby Bottles: Challenges and Perspectives. Eur. Comm. Jt. Res. Cent. Inst. Heal. Consum. Prot. 2010.

10. Corrales, J.; Kristofco, L.A.; Steele, W.B.; Yates, B.S.; Breed, C.S.; Williams, E.S.; Brooks, B.W. Global Assessment of Bisphenol A in the Environment: Review and Analysis of Its Occurrence and Bioaccumulation. Dose-response 2015, 13, 1-29, https://doi.org/10.1177/1559325815598308.

11. Diamanti-Kandarakis, E.; Bourguignon, J.-P.; Giudice, L.C.; Hauser, R.; Prins, G.S.; Soto, A.M.; Zoeller, R.T.; Gore, A.C. Endocrine-disrupting chemicals: an Endocrine Society scientific statement. Endocr. Rev. 2009, 30, 293-342, https://doi.org/10.1210/er.2009-0002.

12. Ohore, O.E.; Zhang, S. Endocrine disrupting effects of bisphenol A exposure and recent advances on its removal by water treatment systems. A review. Sci. African 2019, 5, https://doi.org/10.1016/j.sciaf.2019.e00135.

13. Nomiri, S.; Hoshyar, R.; Ambrosino, C.; Tyler, C.R.; Mansouri, B. A mini review of bisphenol A (BPA) effects on cancer-related cellular signaling pathways. Environ. Sci. Pollut. Res. 2019, 26, 8459-8467, https://doi.org/10.1007/s11356-019-04228-9.

14. Ribeiro, E.; Ladeira, C.; Viegas, S. Occupational Exposure to Bisphenol A (BPA): A Reality That Still Needs to Be Unveiled. Toxics 2017, 5, https://doi.org/10.3390/toxics5030022.

15. Russo, G.; Barbato, F.; Grumetto, L. Monitoring of bisphenol A and bisphenol S in thermal paper receipts from the Italian market and estimated transdermal human intake: A pilot study. Sci. Total Environ. 2017, 599-600, 68-75, https://doi.org/10.1016/j.scitotenv.2017.04.192.

16. Sasso, A.F.; Pirow, R.; Andra, S.S.; Church, R.; Nachman, R.M.; Linke, S.; Kapraun, D.F.; Schurman, S.H.; Arora, M.; Thayer, K.A.; Bucher, J.R.; Birnbaum, L.S. Pharmacokinetics of bisphenol A in humans following dermal administration. Environ. Int. 2020, 144, https://doi.org/10.1016/j.envint.2020.106031.

17. Bernier, M.R.; Vandenberg, L.N. Handling of thermal paper: Implications for dermal exposure to bisphenol A and its alternatives. PLoS One 2017, 12, https://doi.org/10.1371/journal.pone.0178449.

18. Murata, M.; Kang, J.-H. Bisphenol A (BPA) and cell signaling pathways. Biotechnol. Adv. 2018, 36, 311327, https://doi.org/10.1016/j.biotechadv.2017.12.002.

19. Jurek, A.; Leitner, E. Analytical determination of bisphenol a (BPA) and bisphenol analogues in paper products by LC-MS/ MS. Food Addit. Contam. - Part A Chem. Anal. Control. Expo. Risk Assess. 2018, 35 , 2256-2269, https://doi.org/10.1080/19440049.2018.1524157.

20. Lin, Z.; Wang, L.; Jia, Y.; Zhang, Y.; Dong, Q.; Huang, C. A Study on Environmental Bisphenol A Pollution in Plastics Industry Areas. Water, Air, Soil Pollut. 2017, 228, https://doi.org/10.1007/s11270-017-3277-9.

21. Geens, T.; Aerts, D.; Berthot, C.; Bourguignon, J.-P.; Goeyens, L.; Lecomte, P.; Maghuin-Rogister, G.; Pironnet, A.-M.; Pussemier, L.; Scippo, M.-L.; Van Loco, J.; Covaci, A. A review of dietary and non-dietary exposure to bisphenol-A. Food and Chemical Toxicology 2012, 50, 3725-3740, https://doi.org/10.1016/j.fct.2012.07.059.

22. Zhang, P.; Gao, C.; Zhao, B.; Sun, G. Using data mining and UV-VIS spectrophotometric to determine the content of bisphenol A in plastics. J. Chem. Pharm. Res. 2014, 6, 2553-2557.

23. Birkmann, J.; Pasel, C.; Luckas, M.; Bathen, D. UV spectroscopic properties of principal inorganic ionic species in natural waters. Water Pract. Technol. 2018, 13, 879-892, https://doi.org/10.2166/wpt.2018.097.

24. European Food Safety Authority (EFSA), Parma, I. Scientific Opinion on the risks to public health related to the presence of bisphenol A (BPA) in foodstuffs. European Food Safety Authority 2015, 13, https://doi.org/10.2903/j.efsa.2015.3978.

25. Le, H.H.; Carlson, E.M.; Chua, J.P.; Belcher, S.M. Bisphenol A is released from polycarbonate drinking bottles and mimics the neurotoxic actions of estrogen in developing cerebellar neurons. Toxicol. Lett. 2008, 176, 149-156, https://doi.org/10.1016/j.toxlet.2007.11.001.

26. Cooper, J.E.; Kendig, E.L.; Belcher, S.M. Assessment of bisphenol A released from reusable plastic, aluminium and stainless steel water bottles. Chemosphere 2011, 85, 943-947, https://doi.org/10.1016/j.chemosphere.2011.06.060. 
27. Nugroho, B.; Pramudya, Y.; Widodo, W. The Content Analysis of Bisphenol A (BPA) on Water in Plastic Glass with Varying Temperatures and Contact Times using UV-VIS Spectrophotometer. Indones. Rev. Phys. 2019, 1, https://doi.org/10.12928/irip.v1i2.263.

28. Babu, S.; Uppu, S.N.; Martin, B.; Agu, O.A.; Uppu, R.M. Unusually high levels of bisphenol A (BPA) in thermal paper cash register receipts (CRs): development and application of a robust LC-UV method to quantify BPA in CRs. Toxicol. Mech. Methods 2015, 25, 410-416, https://doi.org/10.3109/15376516.2015.1045661.

29. Khan, N.G.; Correia, J.; Adiga, D.; Rai, P.S.; Dsouza, H.S.; Chakrabarty, S.; Kabekkodu, S.P. A comprehensive review on the carcinogenic potential of bisphenol A: clues and evidence. Environ. Sci. Pollut. Res. 2021, 28, 19643-19663, https://doi.org/10.1007/s11356-021-13071-w. 